\title{
Immunohistochemical Expression of VEGF in Relation to Other Pathological Parameters of Breast Carcinoma
}

\author{
Mais Almumen \\ University of Kufa, Najaf, Iraq \\ Email: maisalmumen@yahoo.com
}

Received 4 March 2014; accepted 30 August 2015; published 2 September 2015

Copyright (C) 2015 by author and Scientific Research Publishing Inc.

This work is licensed under the Creative Commons Attribution International License (CC BY). http://creativecommons.org/licenses/by/4.0/

(c) (i) Open Access

\begin{abstract}
Background: Several molecular markers have been detected that are important in clinical aspect of malignancies especially in breast cancer. More recently, the expression of vascular endothelial growth factor (VEGF), the most potent endothelial cell mitogen and also a regulator of vascular permeability, is emerging as a prognostic marker in patients with several types of cancer including breast cancer. This study assessed the expression of VEGF in a series of breast cancers in correlation with HER-2/neu and steroid receptors (ER and PR) in standard clinicopathological parameters in an attempt to clarify its potential clinical importance in Iraqi females of Middle Euphrates area. Findings: The present investigation was performed over a period starting from September 2011 through September 2012. Formalin-fixed, paraffin-embedded blocks from 52 patients with breast cancer (44 ductal and 8 lobular carcinoma) were included in this study. A group of 20 patients with fibroadenoma was included as a comparative group, and 20 samples of normal breast tissue sections were used as controls. Labeled streptavidin-biotin (LSAB+) complex method was employed for immunohistochemical detection of VEGF, HER-2/neu, ER and PR. The detection rate of VEGF, HER-2/neu, ER and PR was 59.62\%, 36.96\%, 34.62\% and $36.54 \%$ respectively. There was a significant difference in immunoexpression between ductal and lobular carcinoma, but not significantly different among tumor sizes, tumor grades, axillary lymph node involvement and age of the patients. However, VEGF was positively correlated with tumor grade, tumor size, nodal involvement and HER-2/neu, but negatively correlated with ER and PR, which show the most unfavorable biopathological profile. Conclusion: VEGF overexpression play an important role in pathogenesis of breast carcinoma evolution, as its positivity associated with biologically aggressive tumors, so incorporation of this biomarker with other parameters into a prognostic index will more accurately predict clinical outcome and determine the effects of anti cancer therapy.
\end{abstract}

\section{Keywords}

Breast Carcinoma, VEGF, ER, PR, IHC 


\section{Introduction}

Breast carcinoma is one of the most important diseases for women and constitutes about one fourth of all cancers, making it the most common cancer in females [1]. Angiogenesis, the development and formation of new blood vessels, is important in a variety of physiological processes, such as growth, differentiation, healing and neoplasia [2]. Sequential interaction of neoplastic cells with this neovasculature is now believed to be one of the most significant steps in metastasis, tumor cells capable of rapid proliferation are thought to be dependent on persistent blood vessels to expand, and the absence of neovascularization will consequently restrict tumor growth. Vascularization is likewise considered to permit shedding of cells from the primary tumor to distant body sites, thus facilitating the metastatic process [3]. Angiogenic and anti-angiogenic factors, secreted by tumor, inflammatory, and stromal cells play an important role in regulation of neovascularization. Among the most important of these is vascular endothelial growth factor (VEGF). This growth factor may be produced in response to environment stimuli, mainly hypoxia, and to stimulation by certain cytokines and estradiol [4]-[6]. It belongs to gene family that includes placental growth factor (PLGF), VEGFB, VEGFC, and VEGFD. Its molecular weight is 34 - $46 \mathrm{kDa}$, size is 232 amino acids, location is 6p12, and alias is VEGFA [7] [8].

Increased VEGF has been shown in several angiogenic processes, both physiological and pathological. VEGF expression has been correlated with high vascularity in tumors, including breast cancer. Expression of VEGF in breast carcinoma has been studied with some contradictory results. This expression has been found to be correlated with tumor size, grade, lymph node status, disease free survival and overall survival [9]-[14]. However, other investigators didn't find any association of VEGF expression with tumor size, lymph node status or disease free survival and overall survival [15]. This study assessed that the expression of VEGF in a series of breast cancers in correlation with HER-2/neu and steroid receptors (ER and PR) in standard clinicopathological parameters is an attempt to clarify its potential clinical importance. HER2/neu (gene map to chromosome 17) is a member of the epidermal growth factor receptor (EGFR) family. Activation of the HER2/neu gene results in synthesis of $185 \mathrm{kD}$ transmembrane protein, whose intracellular domain possesses tyrosine kinase activity and through phosphorylation induction leads to tumor cell proliferation [6].

HER2/neu amplification or overexpression has been shown to be associated with higher grades of tumor and poorer prognosis [6] [16]. With respect to hormone receptors status (estrogen (ER) and progesterone (PR)), breast cancer is considered as a hormone-dependent cancer. In published literatures, approximately $50 \%$ of tumors are ER+ PR+; 25\% ER- PR-; 20\% ER+ PR- and 5\% are ER- PR+ [14] [15]. Indeed, the estrogen receptor (ER) and the progesterone receptor (PR) have been widely accepted as established parameter in the management of patients with primary breast cancer along with HER-2/neu and VEGF status as prognostic markers. Her-2/neu shows overexpression in high grade cancer and displays lower responsiveness to hormone receptors modulators. Hormone receptors positivity inversely correlates with the presence of epidermal growth factor receptor [17].

So biological markers able to predict responsiveness to therapy would be of great help to physicians aiming to select the most appropriate treatment for each patient [16]. The present study is the first to look at the co-expression of these biomarkers in breast tissue samples from Iraqi women of the middle Euphrates area and the results of this work are compared to findings on co-expression of these biomarkers in studies on breast cancer from other parts of the world.

\section{Methods}

Approval for the study was granted by the Iraqi Ministry of Higher Education and Scientific Research Ethics Committee. The Authors wrote to the patients asking if they would be willing to donate their tissues for the project. Families of individuals were also contacted. The samples were taken from consenting individuals and their families.

\subsection{Sampling of Cases}

a) Study group: Fifty two cases of female patients with breast carcinoma (as confirmed by H \& E-stained histopathological examination) were included in this study, their ages ranging between 26 - 70 years with a mean age of 45.96 years, 36 specimens were from modified radical mastectomy and 16 from excisional biopsy. These cases were collected from laboratory of histopathology in Al-Sadder Teaching Medical City Hospital in $\mathrm{Al}$ Najaf and from some private laboratories in the same governorate. 
b) Comparative group: Twenty cases of benign breast lesion (all were fibroadenomas) collected from patients of the same age groups to compare the rate of VEGF, ER, PR and HER-2/neu immunoexpression with malignant breast tissues.

c) Control group: Twenty cases of normal breast tissue were selected from patients of the same age groups presented with breast biopsy other than tumor, and regarded as a control group. Each step was done for the control group in parallel with that for study and comparative groups.

d) Positive control Slides: Parallel positive control sections were processed with each set of immunostaining. Positive controls of breast carcinoma sections which are known to express VEGF, ER, PR and HER-2/neu, respectively were used with each run.

e) Negative controls slides: Sections untreated with primary antibody for (VEGF, ER, PR and HER-2/neu) tumor markers were considered as negative controls for each set of slides.

\subsection{Materials and Equipments}

\subsubsection{Primary Antibody}

for immunohistochemical detection of VEGF, HER-2/neu, ER and PR using Monoclonal Mouse Anti-Human Vascular Endothelial Growth Factor, Code M7273, Dako Denmark A/S Produktionsvej 42 DK-2600 Glostrup, Denmark, Polyclonal Rabbit Anti- Human c-erbB-2 Oncoprotein, Code No. 0485, Dako Denmark A/S Produktionsvej 42 DK-2600 Glostrup, Monoclonal mouse anti-human estrogen receptor $\alpha$, Code No.

Dako cytomation Denmark A/S, Produktionsvej 42, DK-2600 Glostrup, Denmark and Monoclonal mouse antihuman progesterone receptor, Code No. M3569, Dako cytomation Denmark were used as primary antibodies for the detection.

\subsubsection{Antibody Diluents}

with Background Reducing Components; 125 ml, Code S3022, LOT 00002288, Dako North America, Inc. 6392 Via Real Carpentaria, CA 93013 USA used for the VEGF in the dilution range of 1:25 - 1:50, ER and PR in the dilution range of 1:20 and for Her2/neu in the dilution range of 1:200.

\subsubsection{Antigen Retrieval}

Target Retrieval Solution, 500 ml, PH 9, Code S2368, LOT 00026677, Dako Denmark A/S Produktionsvej 42 DK-2600 Glostrup Denmark.

\subsubsection{Buffer Solution}

Tris buffered Saline with Tween 20.10× Concentrate Code S3306 used for VEGF, ER, PR and Her2/neu. Dakocytomation Denmark A/S Produktionsvej 42 DK-2600 Glostrup Denmark. Dako, Inc. 6392 via Real Carpentaria, CA 93013 USA.

\subsubsection{Staining Kit}

Dakocytomation, Code K0679, sufficient for 150 tissue sections, based on 100 microliters per section.

\subsection{Immunohistochemical Staining Protocol}

The immunostaining method used in the current study was Labelled Strept-Avidin Biotin (LSAB+) technique which was applied for VEGF, HER-2/neu, ER and PR staining and included the followings: Tissues: $4 \mu \mathrm{m}$ sections of multi-block with $10 \%$ Formalin fixed and paraffin embedded human tissue. Mounted on Silanized slides (S3003). Primary antibody: Antibodies are diluted in Dako Antibody Diluent (S3022). Control: The negative control is pretreated and then incubated in Antibody Diluent step in the protocol. Deparaffinization: This has been performed previously after the sections were dried for 1 hour at $60^{\circ} \mathrm{C}$. Pretreatments: [Heat induced epitope retrieval in microwave-oven (MWO)].

\subsection{Scoring System}

The criterion for positive immunoreaction is dark brown intracellular (cytoplasmic) precipitate for VEGF, or at the cell membrane for HER-2/neu and in the nucleus for ER and PR. The proportion of the staining was assessed 
by counting the percentage of positive cells in 100 malignant cells at objective 40 total magnifications, each sample was scanned for five fields randomly with a high power magnification (144). Qualitative assessment: Faint staining pattern, whether cytoplasmic, membranous or nuclear, that only could be detected by using higher magnification (objective 40), while strong staining pattern, easily seen by low magnification (objective 4).

a) VEGF Scoring System (Table 1)

b) HER-2/neu Scoring System (Table 2)

c) Estrogen and Progesterone Receptors Scoring System [20]:

A total score (TS) = Sum of Proportion Score (PS) and Intensity Score (IS). A positive result for both ER and PR is defined as TS $\geq 3$ (Table 3, Table 4).

\section{Table 1. VEGF Scoring system [18].}

\begin{tabular}{cc}
\hline Score & Staining pattern \\
\hline Score 0 & Negative, none of the cells revealed positivity for the marker. \\
Score $1+$ & Weak or mild staining, $(5 \%-10 \%)$ positive of tumor cells. \\
Score $2+$ & Moderate staining, less than $25 \%$ of tumor cells are stained positive. \\
Score $3+$ & Strong staining, $(25 \%-50 \%)$ of tumor cells are stained positive. \\
Score $4+$ & Highly strong staining, over $50 \%$ of tumor cells are stained positive. \\
\hline
\end{tabular}

\section{Table 2. Herceptest Scoring system [19].}

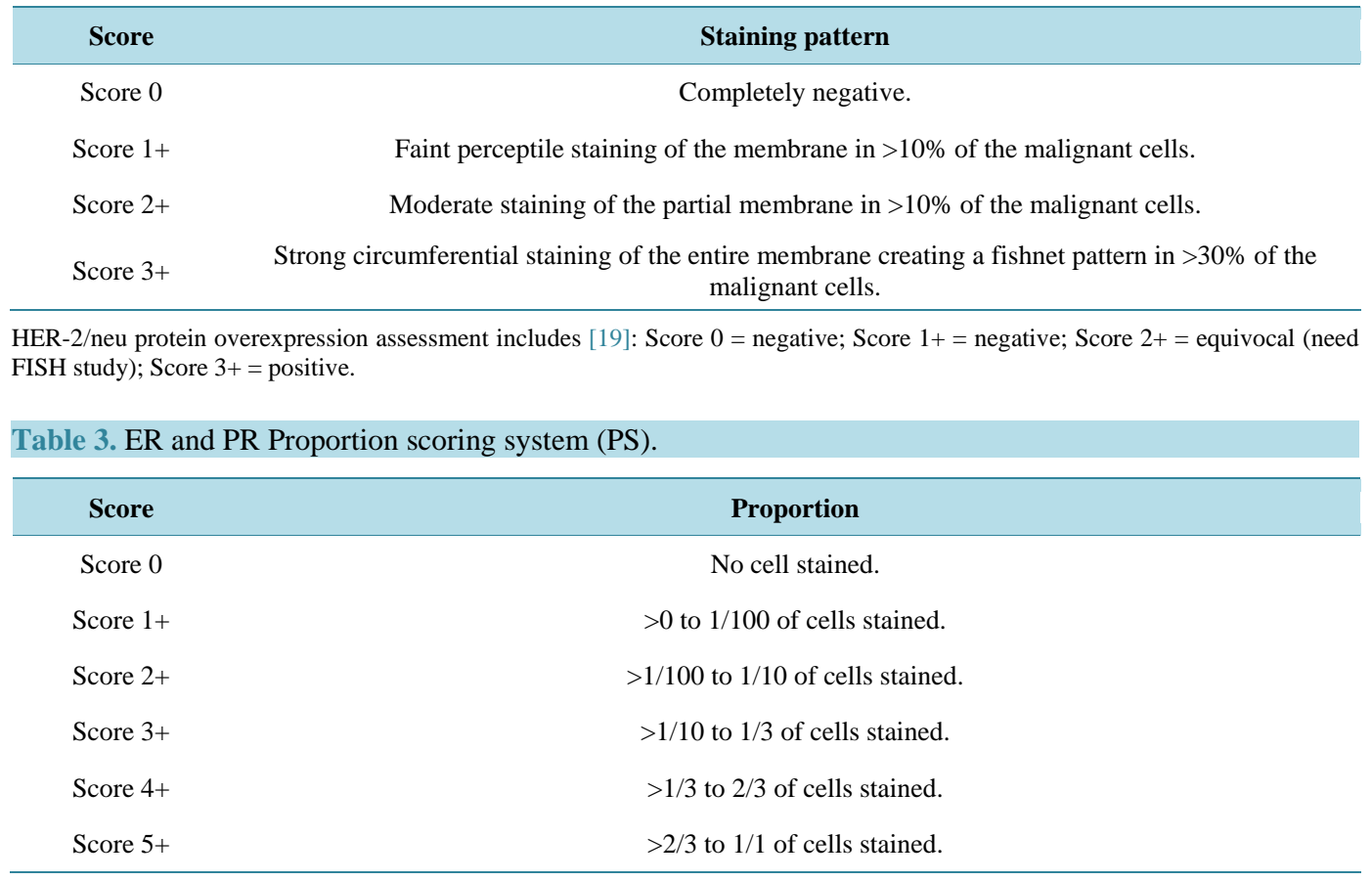

Table 4. ER and PR Intensity scoring system (IS).

\begin{tabular}{cc}
\hline Score & Intensity \\
\hline Score 0 & Negative \\
Score 1 & Week \\
Score 2 & Intermediate \\
Score 3 & Strong \\
\hline
\end{tabular}




\subsection{Statistical Analysis}

All biopsies were classified into three grades: Grade I, Grade II and Grade III, according to the modified Bloom Richardson Grading System [21]. Statistical analyses of all results were performed by the help of SPSS software statistical package (version 15) using Chi Square test, $\mathrm{P}$ value at level of significance $<0.05$ and correlation regression test ( $\mathrm{R}$ at a significant level of 0.3 ).

\section{Results}

Forty four (84.62\%) of the fifty two cases included in this study were of ductal carcinoma while 8 cases (15.38\%) were of lobular type. The detection rate of VEGF, HER-2/neu, ER and PR were 59.62\%, 36.96\%, 34.62\% and $36.54 \%$ respectively. The positivity of VEGF were $0 \%$ in normal breast tissue, $20 \%$ in the benign and $59.62 \%$ in the malignant tissues with a significant difference $(P<0.05)$ (Table 5) in immunoexpression as it also occur between ductal and lobular type carcinoma, but not significantly different among tumor grades, different tumor sizes, axillary lymph node involvement and age of the patients. However, VEGF was positively correlated with tumor grade ( $0 \%$ for grade I, 50\% grade II, $65.79 \%$ grade III), tumor size if excluding in situ component, also with positive nodal involvement (Table 5), also with HER-2/neu (14 out of 17 HER2 positive cases were VEGF positive while 14 out of 29 HER2 negative cases were VEGF positive) (Table 6), but negatively correlated with ER and PR, as explained: (8 out of 18 ER positive cases were VEGF positive while 23 out of 34 ER negative cases were VEGF positive) (Table 7), (10 out of 19 PR positive cases were VEGF positive while 21 out of 33 PR negative cases were VEGF positive) without a significant difference $(P>0.05)$ and these show the most unfavorable biopathological profile.

\section{Discussion}

Breast cancer is a multifactorial disease, the genetic alterations lead to the transformation of normal cells into cancer cells. Human breast cancer is an angiogenesis-dependent tumor that initially depends on estrogens for development and progression [22]. The biology of breast carcinoma remains poorly understood as the knowledge about individual prognostic factors provides limited information [23]. Today, most pathologists considered IHC evaluation of ER/PR receptors as well as c-erbB-2, VEGF and Ki-67 proliferation indices as essential parameters in selecting the line of treatment of breast cancer patient in addition to the traditional tumor/no$\mathrm{dal} /$ metastasis staging variables [24]. Thus, the current study represents a forward step toward understanding the possible role of VEGF during breast cancer development, invasion, and metastasis, moreover, determining ER, PR and HER-2/neu overexpression and their possible correlation to VEGF overexpression in different clinicopathological parameters of breast carcinoma in a series of Iraqi women to select the most appropriate treatment for each patient. The current study demonstrated that although completely absent expression from normal breast tissue and relatively little expression in benign breast lesions, conversely there was a significant overexpression of VEGF among the 52 investigated breast carcinoma (P value $<0.05$ ). The results have clarified that $59.62 \%$ of breast cancer cases were expressing VEGF immunostaining in their histological sections (Table 5). Our results are near to those reported by other investigators [9] [11] [22] [25] [26], without any significant difference between our results and these results $(\mathrm{P}>0.05)$, while they are higher than those reported by some others [27]-[29].

Immunoexpression of VEGF for ductal carcinomas was higher than that of infiltrating lobular carcinomas (65.91\% versus $25 \%)$ with a significant difference $(\mathrm{P}<0.05)$ (Table 5$)$. Thus, supporting the view that such tumors represent a defined subtype of breast carcinoma. The current study revealed $100 \%$ of pure DCIS and DCIS with invasive component were VEGF positive. It looks that VEGF may play a role in cancer progression from CIS to invasive form, and may influence aggressiveness indirectly through its effect on angiogenesis, furthermore, it acts as an autocrine survival for the tumor cells themselves as documented by many researches [30] [31]. These results are supporting the hypothesis that VEGF plays important role in initiation and progression of ductal carcinomas. Although positive correlation with higher grades was detected, there is no significant difference among these grades $(\mathrm{R}>0.3, \mathrm{P}>0.05)$. This fact has been documented by many investigators [9] [13] [32]-[34].The unexpected findings may be due to disproportionate total number of cases in grade II and III (12 versus 38) which may interrupt the significant association (Table 5). Another explanation is that as the tumor advances, other biological changes may occur that reduce the requirement for continued VEGF signaling, these changes reflect the aggressive behavior of tumor and the reduced degree of tumor differentiation. It looks that 
Table 5. Relationship between VEGF immunoexpression and clinicopathological parameters of breast carcinoma.

\begin{tabular}{|c|c|c|c|c|c|}
\hline \multirow[b]{2}{*}{ Parameters } & \multirow{2}{*}{$\begin{array}{c}\text { Total number of } \\
\text { patients No. } \%\end{array}$} & \multicolumn{2}{|c|}{ VEGF immunoexpression } & \multirow{2}{*}{ P value } & \multirow[b]{2}{*}{$\mathbf{R}$ test } \\
\hline & & Positive No. \% & $\begin{array}{l}\text { Negative } \\
\text { No. } \%\end{array}$ & & \\
\hline \multicolumn{6}{|l|}{ Type of breast tissue } \\
\hline Normal & 20 (17.39) & $0(0)$ & $20(100)$ & \multirow{3}{*}{$\mathbf{P}<0.05$} & \multirow{3}{*}{$\mathbf{R}>\mathbf{0 . 3}$} \\
\hline Benign (fibroadenoma) & $20(21.74)$ & $4(20)$ & $16(80)$ & & \\
\hline Malignant & $52(60.87)$ & $31(59.62)$ & $21(40.38)$ & & \\
\hline \multicolumn{6}{|l|}{ Histological type } \\
\hline Lobular carcinomas & $8(15.38)$ & $2(25)$ & $6(75)$ & \multirow[t]{2}{*}{$P<0.05$} & \\
\hline Ductal carcinomas & $44(84.62)$ & $29(65.91)$ & 15 (34.09) & & \\
\hline \multicolumn{6}{|l|}{ Including: } \\
\hline Pure IDC & $29(55.78)$ & $14(48.28)$ & $15(51.72)$ & \multirow{4}{*}{$\mathbf{P}<0.05$} & \\
\hline IDC + DCIS & $8(15.38)$ & $8(100)$ & $0(0)$ & & \\
\hline IDC + Paget’s & $4(7,69)$ & $4(100)$ & $0(0)$ & & \\
\hline Pure DCIS & $3(5.77)$ & $3(100)$ & $0(0)$ & & \\
\hline \multicolumn{6}{|l|}{ Tumor grade } \\
\hline I & $2(3.84)$ & $0(0)$ & $2(100)$ & \multirow{3}{*}{$P>0.05$} & \multirow{3}{*}{$\mathbf{R}>\mathbf{0 . 3}$} \\
\hline II & $12(23.08)$ & $6(50)$ & $6(50)$ & & \\
\hline III & $38(73.08)$ & 25 (65.79) & $13(34.21)$ & & \\
\hline \multicolumn{6}{|l|}{ Tumor size } \\
\hline Tis & $3(5.77)$ & $3(100)$ & $0(0)$ & \multirow{5}{*}{$\mathbf{P}>0.05$} & \multirow{5}{*}{$\mathbf{R}>\mathbf{0 . 3}$} \\
\hline $\mathrm{T} 1(\leqslant 2 \mathrm{~cm})$ & $6(11.54)$ & $1(16.67)$ & $5(83.33)$ & & \\
\hline $\mathrm{T} 2(2>-5 \mathrm{~cm})$ & $24(46.15)$ & $14(58.33)$ & $10(41.67)$ & & \\
\hline $\mathrm{T} 3(>5 \mathrm{~cm})$ & $15(28.85)$ & $9(60)$ & $6(40)$ & & \\
\hline T4 (anyT+other) & $4(7.69)$ & $4(100)$ & $0(0)$ & & \\
\hline \multicolumn{6}{|l|}{ Axillary lymph nodes } \\
\hline Negative & $11(30.56)$ & $5(45.45)$ & $6(54.55)$ & \multirow[t]{2}{*}{$P>0.05$} & $\mathbf{R}>\mathbf{0 . 3}$ \\
\hline Positive & 25 (69.44) & $16(64)$ & $9(36)$ & & \\
\hline \multicolumn{6}{|l|}{ Age of the patient } \\
\hline $21-30$ years & $9(17.31)$ & $6(66.67)$ & 3 (33.33) & \multirow{5}{*}{$P>0.05$} & \\
\hline $31-40$ years & $8(15.38)$ & $6(75)$ & $2(25)$ & & \\
\hline 41 - 50 years & 17 (32.69) & 12 (70.59) & $5(29.41)$ & & \\
\hline $51-60$ years & $5(9.62)$ & $2(40)$ & $3(60)$ & & \\
\hline $61-70$ years & $13(25)$ & $5(38.46)$ & 8 (61.54) & & \\
\hline
\end{tabular}

the detection rate of VEGF is increasing as the size of tumor increased $(\mathrm{R}>0.3)$ without a significant difference ( $\mathrm{P}>0.05)$ among different tumor sizes if in situ components were excluded from the data (Table 5).

Similar findings found by other researches [17] [18], but many papers documented that there is a negative correlation between VEGF expression and size of tumor [26] [32] [35] [36]. This might be attributed to the effect of hypoxia, the most important stimulator of VEGF production, which becomes more profound as the size of the tumor increases. VEGF immunoexpression is higher in node positive breast cancer than in node negative without a significant difference between them (Table 5). This finding against what was suggested by one study in 
Table 6. Coexpression of VEGF and HER-2/neu in relation to their separate and neither expression in breast carcinoma.

\begin{tabular}{cccc}
\hline Immunostaining & VEGF positive & VEGF negative & Total \\
\hline HER-2/neu positive & $14(50 \%)$ & $3(16.67 \%)$ & $\mathbf{1 7}(\mathbf{3 6 . 9 6 \% )}$ \\
HER-2/neu positive & $14(50 \%)$ & $15(83.33 \%)$ & $\mathbf{2 9}(\mathbf{6 3 . 0 4 \% )}$ \\
Total & $28(60.87 \%)$ & $18(39.13 \%)$ & $\mathbf{4 6}(\mathbf{1 0 0 \% )}$ \\
\hline
\end{tabular}

Table 7. Coexpression of VEGF and ER in relation to their separate and neither expression in breast carcinoma.

\begin{tabular}{cccc}
\hline Immunostaining & VEGF positive & VEGF negative & Total \\
\hline ER positive & $8(25.81 \%)$ & $10(47.62 \%)$ & $\mathbf{1 8 ~ ( 3 4 . 6 2 \% )}$ \\
ER negative & $23(74.19 \%)$ & $11(52.38 \%)$ & $\mathbf{3 4}(\mathbf{6 5 . 3 8 \% )}$ \\
Total & $31(59.62 \%)$ & $21(40.38 \%)$ & $\mathbf{5 2 ( 1 0 0 \% )}$ \\
\hline
\end{tabular}

(2003) [26], but agreed with what was reported by others [23] [33] [37]-[40] and this may be attributed to the aggressive behavior of node positive breast cancer. The results of this study revealed that there was no significant difference in VEGF immunoexpression among different age groups, this may be corresponding to the natural frequency of breast cancer. HER-2/neu positivity was documented in 14 (50\%) out of 28 cases with positive VEGF immunoexpression, there is positive correlation with a significant difference (Table 6). This finding agreed with many studies [41]-[43]. ER positivity was seen in 8 (25.81\%) out of 31 cases with positive VEGF immuno-expression, without a significant difference (Table 7). This finding agreed with many authors [10] [22] [29] [41] [42] [44]-[47].

The above authors proposed several possible explanations, including limitation of tumor growth by vascular compression, interstitial pressure, and necrosis; a lack of specific receptors for soluble ER isoforms in this subgroup of high VEGF expressing tumors; overexpression of endo-genous angiogenic inhibitors; or the distortion of results due to relatively small number of patients in this subgroup which also may be a factor affecting the study results. VEGF expression may be regulated by estrogen and has been correlated with ER-negative status and associated with response to anti estrogen therapy. PR positivity was seen in 10 (32.26\%) out of 31 cases with positive VEGF immunoexpression, without a significant difference. This finding agreed with some researches [41] [44]. The absence of such association is anticipated because breast cancers express numerous angiogenic factors that act in concert to generate the tumor vasculature as it is interacting with hormonal receptors. These differences may also reflect the effect of varying therapeutic regimens on the interaction with steroid receptors.

\section{Conclusions}

In conclusion, normal and benign breast tissues did not express a significant immunohistochemical level of VEGF. VEGF overexpression is a hallmark of bad prognosis as it was associated with worse biopathological parameters, such as tumor size. VEGF immunoexpression was positively correlated with HER-2/neu, while inversely correlated with ER and PR immunoexpression. Incorporation of these biomarkers with other factors into a prognostic index will more accurately predict clinical outcome and determine the effect of anti cancer therapy.

Large prospective clinical studies with a longer duration of follow-up and studying the survival rates will provide a better insight and validate our findings and are needed to better clarify the prognostic role of VEGF in breast cancer. Considering further studies including DNA/mRNA and protein levels by FISH or PCR techniques to confirm the molecular basis of these genes alteration and to reveal which members of the VEGF family might possibly be useful in identifying those patients who will benefit most from anti-VEGF strategies.

\section{Competing Interests}

The author declared that she had no competing interests. 


\section{References}

[1] Singhal, H., Gohel, M.S., Kaur, K. and Thomson, S. (2008) Breast Cancer Evaluation. eMedicine Journal Specialty, 2-10.

[2] Folkman, J. and Klagsbrun, M. (1987) Angiogenic Factors. Science, 235, 442-447. http://dx.doi.org/10.1126/science.2432664

[3] Folkman, J. (1989) What Is the Evidence that Tumors Are Angiogenesis Dependent? Journal of the National Cancer Institute, 82, 4-6. http://dx.doi.org/10.1093/jnci/82.1.4

[4] Drovak, H.F., Brown, L.F., Detmar, M. and Dvorak, A.M. (1995) Vascular Permeability Factor/Vascular Endothelial Growth Factor, Microvascular Hyperpermeability, and Angiogenesis. American Journal of Pathology, 146, 1029-1039.

[5] Ferrara, N. and Alitalo, K. (1999) Clinical Application of Angiogenic Growth Factors and Their Inhibitors. Nature Medicine, 5, 1359-1364. http://dx.doi.org/10.1038/70928

[6] Nicosia, R.F. (1998) What Is the Role of Vascular Endothelial Growth Factor-Related Molecules in Tumor Angiogenesis? The American Journal of Pathology, 153, 11-16. http://dx.doi.org/10.1016/S0002-9440(10)65539-3

[7] Jung, L., Bałan, B.J., Różewska, E.S., Wynimko, J.C., Siwicki, A.K., Sommer, E., et al. (2007) Clinical Immunology VEGF in Circulating Blood of Patients Treated with Enoxaparine after Orthopaedic Surgery. Central European Journal of Immunology, 32, 61-65.

[8] Ferrara, N. (1999) Molecular and Biological Properties of Vascular Endothelial Growth Factor. Journal of Molecular Medicine, 77, 527-543. http://dx.doi.org/10.1007/s001099900019

[9] Linderholm, B., Tavelin, B. and Grankvist, K. (1998) Vascular Endothelial Growth Factor is of High Prognostic Value in Node-Negative Breast Carcinoma. Journal of Clinical Oncology, 16, 3121-3128.

[10] Linderholm, B., Lindh, B., Tavelin, B., Grankvist, K. and Henriksson, R. (2000) p53 and Vascular-EndothelialGrowth-Factor (VEGF) Expression Predicts Outcome in 833 Patients with Primary Breast Carcinoma. International Journal of Cancer, 89, 51-62. http://dx.doi.org/10.1002/(SICI)1097-0215(20000120)89:1<51::AID-IJC9>3.0.CO;2-8

[11] Toi, M., Hoshina, S. and Takayanagi, T. (1994) Association of Vascular Endothelial Growth Factor Expression with Tumor Angiogenesis and with Early Relapse in Primary Breast Cancer. Japanese Journal of Cancer Research, 85, 1045-1049. http://dx.doi.org/10.1111/j.1349-7006.1994.tb02904.x

[12] Toi, M., Inada, K., Suzuki, H. and Tominaga, T. (1995) Tumor Angiogenesis in Breast Cancer. Breast Cancer Research and Treatment, 36, 193-204. http://dx.doi.org/10.1007/BF00666040

[13] Valkovic, T., Dobrila, F., Melato, M., Sasso, F., Rizzardi, C. and Jonjic, N. (2002) Correlation between Vascular Endothelial Growth Factor, Angiogenesis, and Tumor-Associated Macrophages in Invasive Ductal Breast Carcinoma. Virchows Archiv, 440, 583-588. http://dx.doi.org/10.1007/s004280100458

[14] Wang, F., Wei, L. and Chen, L. (2000) The Relationship between Vascular Endothelial Growth Factor, Microvascular Density, Lymph Node Metastasis and Prognosis of Breast Carcinoma. Chinese Journal of Pathology, 29, 172-175.

[15] MacConmara, M., O’Hanlon, D.M., Kiely, M.J., Connolly, Y., Jeffers, M. and Keane, F.B. (2002) An Evaluation of the Prognostic Significance of Vascular Endothelial Growth Factor in Node Positive Primary Breast Carcinoma. International Journal of Oncology, 20, 717-721. http://dx.doi.org/10.3892/ijo.20.4.717

[16] Ferrara, N. and Henzel, W.J. (1989) Pituitary Follicular Cells Secrete a Novel Heparin-Binding Growth Factor Specific for Vascular Endothelial Cells. Biochemical and Biophysical Research Communications, 84, 856-861. http://dx.doi.org/10.1016/0006-291x(89)92678-8

[17] World Health Organization International Agency for Research on Cancer (2003) World Cancer Report, 335.

[18] Apple, S.K., Hecht, J.R., Lewin, D.N., Jahromi, S.A., Grody, W.W. and Nieberg, R.K. (1999) IHC Evaluation of K-ras, P53, and Her2/neu Expression in Hyperplasic, Dysplastic, and Carcinomatous Lesions of the Pancreas: Evidence for Multistep Carcinogenesis. Human Pathology, 30, 123-129. http://dx.doi.org/10.1016/S0046-8177(99)90265-4

[19] Truls, G., Kennet, W. and Jörgen, C. (2005) Analysis of Her2/neu Expression in Primary Bladder Carcinoma and Corresponding Metastases. Journal of Pathology, 95, 982-986.

[20] (2011) Dakocytomation Catalog for Products and Services. Dako, Glostrup, 139-143.

[21] Elston, C.W. and Ellis, I.O. (1991) Pathological Prognostic Factors in Breast Cancer. I. The Value of Histological Grade in Breast Cancer: Experience from a Large Study with Long-Term Follow-Up. Histopathology, 19, 403-410. http://dx.doi.org/10.1111/j.1365-2559.1991.tb00229.x

[22] Gasparini, G., Toi, M., Miceli, R., Vermeulen, P.B., Dittadi, R., Biganzoli, E., et al. (1999) Clinical Relevance of VEGF and Thymidine Phosphorelase in Patients with Node-Positive Breast Cancer Treated with Either Adjuvant Chemotherapy or Hormone Therapy. The Cancer Journal from Scientific American, 5, 101-112.

[23] Sorli, T., Perou, C.M., Tibshirani, R., Aas, T., Geisler, S., Johnsen, H., et al. (2001) Gene Expression Patterns of Breast 
Carcinomas Distinguishes Tumor Subclasses with Clinical Implication. Proceedings of the National Academy of Sciences of the United States of America, 98, 10869-10874. http://dx.doi.org/10.1073/pnas.191367098

[24] Allred, D.C., Harvey, J.M., Berardo, M. and Clark, G.M. (1998) Prognostic and Predictive Factors in Breast Cancer by Immunohistochemical Analysis. Modern Pathology, 11, 155-168.

[25] Granato, A.M., Nanni, O., Falcini, F., Folli, S., Mosconi, G., Paola, F.D., et al. (2004) bFGF and VEGF Serum Levels in Breast Cancer Patients and Healthy Women. Breast Cancer Research, 6, R38-R45. http://dx.doi.org/10.1186/bcr745

[26] Li, J., Song, S.T., Jiang, Z.F., Liu, X.Q. and Yan, L.D. (2003) Significance of Microvascular Density and VEGF in Breast Cancer. Chinese Journal of Oncology, 25, 145-153.

[27] Ihemelandu, C.U., Leffall, L.D., Naab, T.J. and Fredrieck, W.A. (2007) Expression of VEGF, p53 in Molecular Breast Cancer Subtypes of Pre-Menopausal African-American Women. Journal of Clinical Oncology, 25.

[28] Matkowski, R., Gisterek, I., Suder, E., Lacko, A., Szelachowska, J., Ramsey, D. and Kornafel, J. (2006) Correlation between VEGF and C-Met Expressions in Breast Carcinoma. Journal of Clinical Oncology, 24.

[29] Elli, I., Charchanti, A., Briasoulis, E., Karavasilis, V., Batsis, C., Pavlidis, N., et al. (2002) The Prognostic Value of Vascular Endothelial Growth Factor (VEGF) in Invasive Breast Cancer: Correlation with Microvessel Density (MVD), ER, PgR, p53 and Proliferative Associated Indices (Ki-67, PCNA). Electronic Journal of Pathology and Histology, 8, 024-007.

[30] Harmey, J.H. and Bouchier-Hayes, D. (2002) VEGF, a Survival Factor for Tumour Cells: Implications for AntiAngiogenic Theraoy. Bioassays, 24, 280-283. http://dx.doi.org/10.1002/bies.10043

[31] Bachelder, R.E., Crago, A., Chung, J., Wendt, M.A., Shaw, L.M., Robinson, G. and Mercurio, A.M. (2001) VEGF Is an Autocrine Survival Factor for Neuropilin-Expressing Breast Carcinoma Cells. Cancer Research, 61, 5736-5776.

[32] Halimi, M., Vahedi, A. and Mostafapour, E.K. (2012) Association of VEGF with Regional Lymph Node Metastasis in Breast IDC. Journal of Medical Sciences, 12, 18-23. http://dx.doi.org/10.3923/jms.2012.18.23

[33] Xu, W., Wang, G., Zou, Y., Song, J., Yang, X. and Wang, W. (2007) VEGF Expression in IDC of Breast. Chinese Journal of Cancer Research, 19, 56-59. http://dx.doi.org/10.1007/s11670-007-0056-y

[34] Bolat, F., Kayaselcuk, F., Nursal, T.Z., Yagmurdur, M.C., Bal, N. and Demirhan, B. (2006) Microvessel Density, VEGF Expression, and Tumor Associated Macrophages in Breast Tumors. Journal of Experimental \& Clinical Cancer Research, 25, 365-437.

[35] Macolm, M., Deidre, O.M., James, K.M., Yvonne, C., Michael, J. and Keane, F.B. (2002) An Evaluation of the Prognostic Significance of VEGF in Node Positive Primary Breast Carcinoma. The Internet Journal of Oncology, 20, 717721.

[36] Gasparini, G., Toi, M., Gion, M., Verderio, P., Dittadi, R., Hanatani, M., et al. (1997) Prognostic Significance of VEGF Protein in Node-Negative Breast Carcinoma. Journal of the National Cancer Institute, 89, 139-186. http://dx.doi.org/10.1093/jnci/89.2.139

[37] Hao, L., Zhang, C., Qiu, Y., Wang, L., Luo, Y., Jin, M., et al. (2007) Recombination of CXCR4, VEGF, and MMP-9 Predicting Lymph Node Metastasis in Human Breast Cancer. Cancer Letters, 253, 34-42. http://dx.doi.org/10.1016/j.canlet.2007.01.005

[38] Wang, X.B., Yang, Q.X. and Pei, X.J. (2006) Expression of Angiogenesis-Related Factors in Invasive Breast Cancer and Its Clinical Significance. Journal of Southern Medical University, 26, 860-863.

[39] Hu, S.E., Zhang, Y.J., Cui, Y.M. and Zhang, H.Q. (2005) Expression of VEGF-A and -C in Human Breast Cancer and Their Significance. Chinese Journal of Cancer, 24, 1076-1085.

[40] Yi, W.J., Tang, Z.H., Yang, Z.L., Yu, M.Y., Li, Y.S. and Chen, G.N. (2003) Difference in Expression of VEGF, bFGF and Their Receptors between the Young and Postmenapaosal Women with Breast Cancer. Chinese Journal of Oncology, 25, 141-145.

[41] Linardou, H., Kalogeras, K.T., Kronenwett, R., Kouvatseas, G., Wirtz, R.M., Zagouri, F., et al. (2012) The Prognostic and Predictive Value of mRNA Expression of Vascular Endothelial Growth Factor Family Members in Breast Cancer: A Study in Primary Tumors of High-Risk Early Breast Cancer Patients Participating in a Randomized Hellenic Cooperative Oncology Group Trial. Breast Cancer Research, 14, R145. http://dx.doi.org/10.1186/bcr3354

[42] Fuckar, D., Dekanic, A. and Stifter, S. (2006) VEGF and Other Common Tumor Markers in Breast Cancer. International Journal of Surgical Pathology, 14, 49-55. http://dx.doi.org/10.1177/106689690601400109

[43] Konecny, G.E., Meng, Y.G., Untch, M., Wang, H.J., Bauerfeind, I., Epstein, M., Stieber, P., et al. (2004) Association between HER-2/neu and VEGF Expression Predicts Clinical Outcome in Primary Breast Cancer Patients. Clinical Cancer Research, 10, 1706-1716. http://dx.doi.org/10.1158/1078-0432.CCR-0951-3

[44] Yavuz, S., Paydas, S., Disel, U., Zorludemir, S. and Erdogan, S. (2005) VEGF-C Expression in Breast Cancer: Clinical Importance. Advances in Therapy, 22, 368-380. http://dx.doi.org/10.1007/BF02850084 
[45] Buteau-Lozano, H., Ancelin, M. and Lardeux, B. (2002) VEGF and Other Common Tumor Markers in Breast Cancer. Cancer Research, 62, 4977-4984.

[46] Sarah, P.G., Margaret, J.C., Cheng, H., et al. (2000) The Short Form of the Alternatively Spliced Flt-4 but Not Its Ligand Vascular Endothelial Growth Factor C Is Related to Lymph Node Metastasis in Human Breast Cancers. Clinical Cancer Research, 6, 4278-4286.

[47] Dakocytomation General Instructions for Immunohistochemical Staining: Manual instructions to the Universal Dakocytomation, LSAB, Dako, Denmark, 2004.

\section{List of Abbreviations}

LSAB+: $\quad$ Labeled Streptavidin-biotin,

EGFR: $\quad$ epidermal growth factor receptor,

ER: $\quad$ estrogen,

PR: progesterone,

IHC: immunohistochemistry,

DCIS: ductal carcinoma in situ. 